\title{
FILOSOFIA E BIOÉTICA NO DEBATE PÚBLICO BRASILEIRO
}

Darlei Dall'Agnol*

\section{Introdução}

Os grandes filósofos sempre refletiram e discutiram publicamente questões que hoje denominamos "bioéticas": Platão defendeu uma forma particular de eugenia; Aristóteles e Tomás de Aquino analisaram o problema da interrupção de uma gestação humana; Sêneca, Hume e Kant examinaram a proibição ou não do suicídio que, por analogia, pode ser associada ao problema da eutanásia; Wittgenstein criticou o cientificismo e alertou para alguns perigos da técnica moderna, etc. É claro que muitas questões bioéticas surgiram somente no final do século XX com o advento da biologia molecular, da biomedicina e de tecnologias médicas tais como: reprodução humana assistida; transplantes; hemodiálise; ventilação mecânica; alimentação parenteral, etc. e as inúmeras questões éticas por elas suscitadas. É importante também lembrar o impacto dos três megaprojetos: Manhattan, Apollo e Genoma Humano, seus usos e suas implicações morais. Os problemas bioéticos, todavia, talvez não sejam substancialmente diferentes daqueles que tradicionalmente foram examinadas na Ética pela filosofia.

Em nosso país, entretanto, a participação de filósofos ou profissionais ligados à filosofia em debates públicos sobre questões bioéticas é bastante incipiente. Como compreender essa lacuna?

* Doutor pela University of Bristol (Inglaterra), professor associado do Departamento de Filosofia da Universidade Federal de Santa Catarina (UFSC) e pesquisador do CNPq. E-mail: ddarlei@yahoo.com 
$196 \mid$

Filosofia e bioética no debate público brasileiro

Como explicá-la? Como superá-la? Refletir sobre essas questões é o principal objetivo do presente trabalho. Para alcançá-lo, dividirei o artigo em três partes. Na primeira, vou reconstruir brevemente o surgimento e o desenvolvimento do que hoje chamamos "Bioética" e o papel que os filósofos tiveram nos debates públicos. Na segunda parte, vou procurar estabelecer algumas tarefas que, na minha opinião, a filosofia pode desempenhar na discussão de temas bioéticos. Finalmente, vou ilustrar a necessidade da filosofia para o debate público brasileiro sobre questões bioéticas não apenas sobre os fundamentos éticos da moralidade, mas também questões específicas de aplicação relacionadas com o início, meio e fim da vida.

Antes de iniciar, gostaria de fazer um alerta. Não sou um bioeticista profissional, mas um filósofo, ou melhor, um professor e pesquisador em filosofia. Por conseguinte, a perspectiva a partir da qual escrevo é a da reflexão filosófica sobre as questões bioéticas. Mas há uma tonalidade pessoal neste artigo, espero não subjetiva, pois procuro relatar um pouco da minha experiência para o debate público atual no Brasil.

\section{1 - O papel dos filósofos no surgimento e desenvolvimento da} Bioética

Sabe-se, hoje, que o termo "Bioética" foi usado pela primeira vez pelo teólogo alemão Fritz Jahr, em 1927, e foi, posteriormente, popularizado no início da década de 1970 pelo biólogo e oncologista norte-americano Van R. Potter. Num artigo intitulado "Bio-Ethik" para a revista Kosmos, Fritz Jahr, refletindo tanto sobre as tradições filosóficas e religiosas ocidentais (há menções explícitas a Rousseau, Schopenhauer, São Francisco, etc.) quanto orientais (budismo, hinduísmo, etc.), propôs o seguinte imperativo bioético reformulando a ética de Kant: "Respeite cada ser vivo por princípio como fim em si e trate-o, se possível, como tal" (Jahr, 2011, p. 245). A filosofia, por conseguinte, fez-se presente no próprio nascimento da Bioética. Esse princípio procura elevar o padrão humano de tratamento dos animais e até mesmo das plantas, ou seja, de todas 
as formas de vida. Essa atribuição de valor intrínseco a todo ser vivo foi mais tarde desenvolvida a partir da chamada "Ética da Terra", de Aldo Leopold, na década de 1950 e, posteriormente, pela Ecologia Profunda de Albert Schweitzer. Essas ideias foram importantes no movimento ecológico e no estabelecimento de uma Ética Ambiental e fazem parte do que se pode chamar Bioética "Geral" ou "Global" ou "Holística". Muito provavelmente foi a partir desses trabalhos que Potter propôs usar o termo 'Bioética' para re-unir fatos biológicos e valores morais construindo uma "nova sabedoria" (new wisdom) capaz de proporcionar o "conhecimento de como usar o conhecimento" (knowledge of how to use knowledge) para a sobrevivência do homem e para a melhoria da qualidade de vida (Potter, 1971, p. 1). Na visão de Potter, então, a Bioética seria uma nova forma de sabedoria, necessária para a sobrevivência do homem, baseada na ciência da biologia e em elementos das ciências sociais e humanas "com ênfase na filosofia no seu sentido estrito" (Potter, 1971, p. 2), resultando, portanto, numa ética interdisciplinar, uma ponte entre humanas e ciências naturais.

Uma contribuição importante de um filósofo para o estabelecimento da Bioética, agora enquanto disciplina acadêmica ou campo de estudos, foi a de Daniel Callahan. Doutor em filosofia pela Universidade de Harvard, Callahan fundou em 1969 o "Institute for Society, Ethics, and the Life Sciences" que atualmente é conhecido como "Hastings Center", um instituto de ensino e pesquisa independente que estimula a discussão pública sobre questões bioéticas. O Instituto publica o famoso "Hastings Center Report". Foi nessa revista que Callahan publicou em 1973 um artigo importantíssimo chamado "Bioethics as a Discipline" discutindo o papel do (bio)eticista no mundo da medicina e da biologia. Esse artigo será comentado na segunda seção do presente trabalho.

Outro passo decisivo para o estabelecimento da Bioética enquanto disciplina foi a criação, em 1971, do Kennedy Institute of Ethics, na Georgetown University, Washington DC. Considerado um dos pioneiros da Bioética, como a entendemos hoje, ou seja, 
|98|

Filosofia e bioética no debate público brasileiro

associada principalmente a problemas éticos nas ciências da saúde, André Hellergers direcionou a Bioética para a biomedicina. Foi ali que, em 1972, iniciou-se o planejamento para publicar a Encyclopedia of Bioethics, que define a Bioética como um estudo das dimensões éticas da medicina e das ciências biológicas à luz de valores e princípios morais. Esse é o significado que passou a predominar e que, hoje, é melhor referido, por exemplo, como Bioética Clínica contrapondo-se à Bioética Fundamental. Foi o Kennedy Institute of Ethics que organizou anualmente o "Intensive Bioethics Course", atualmente na sua $38^{a}$ edição, propagador da teoria bioética predominante, a saber, o enfoque dos quatro princípios (ou simplesmente "principialismo") que será comentado a seguir. Esse curso intensivo atraiu gente do mundo todo, inclusive brasileiros, e contribuiu para a divulgação do enfoque normativo mais importante da Bioética. Ali atuam eminentes bioeticistas tais como Edmund Pellegrino, Robert Veacth e Tom Beauchamp.

A participação mais significativa de filósofos foi, todavia, a que se deu em torno da elaboração do Relatório Belmont. Como é amplamente sabido, o Congresso Americano criou, a partir do escandaloso caso Tuskegee, em 1974, uma Comissão Nacional para estabelecer princípios que deveriam nortear as experiências científicas envolvendo seres humanos. A comissão, interdisciplinar e com representantes da sociedade defensores dos direitos civis (humanos), contou com a participação de um filósofo, Albert Jonsen, proponente de um enfoque casuístico da Ética, como membro efetivo. A comissão buscou também o assessoramento de dois outros filósofos, do wittgensteiniano Stephen Toulmin, autor do artigo "How Medicine Saved the Life of Ethics" e do utilitarista Tom Beauchamp, especialmente contratado para propor uma espécie de "Constituição da Bioética", ou seja, um conjunto de princípios éticos para nortear as experiências científicas envolvendo humanos. Segundo Jonsen (2003, p. 103), a comissão adotou os princípios propostos por Tristian Engelhardt, a saber, respeito pelas pessoas enquanto agentes autônomos e a beneficência, ou seja, a preocupação de não causar dano aos sujeitos da pesquisa e, ao mesmo tempo, trazer benefícios para a sociedade e o princípio 
proposto por Beauchamp de justiça distributiva. O documento foi escrito por Beauchamp e re-escrito por Toulmin e, segundo Jonsen, a versão final é sua, ou seja, o Relatório Belmont tal como o conhecemos hoje, publicada em 1978. Mais tarde, o filósofo Tom Beauchamp, defensor de uma ética consequencialista, e o teólogo James Childress, defensor de uma ética deontologista, talvez discordando de alguns pontos centrais do Relatório Belmont, publicaram o "livro sagrado" da Bioética Principles of Biomedical Ethics, hoje na sua sexta edição, defendendo quatro princípios: respeito pela autonomia, não maleficência, beneficência e justiça. Esses princípios tornaram-se o referencial padrão mundo afora e são a base da legislação brasileira relacionada com pesquisa envolvendo seres humanos, seja da Resolução 196, seja da Instrução Normativa 9 da CTNbio. A elaboração do Relatório Belmont, portanto, pode ser considerada uma das contribuições mais significativas de filósofos para o desenvolvimento da Bioética. Foi a partir da "Constituição da Bioética", do livro de Beauchamp e Childress e do Intensive Bioethics Course que o principialismo entrou na base da legislação brasileira que trata da experimentação científica com seres humanos.

Cabe destacar, aqui, também a criação da revista The Journal of Medicine E Philosophy, editada desde 1976. Na sua primeira edição, o já aludido médico e filósofo Edmund Pellegrino, apresentando a revista, escreveu que "a medicina e as ciências da saúde são muito importantes para o futuro do homem para permanecer sem exame. A filosofia também é muito importante para não ser nutrida pela riqueza experiencial da medicina contemporânea." Desde então, Pellegrino destacou-se por trabalhar filosoficamente as questões ontológicas, epistêmicas e éticas da medicina sendo um dos seus trabalhos mais importantes a proposta do modelo da beneficênciana-confiança tal como é expresso no livro For the Patient's Good, um livro que está sendo traduzido e será publicado na Série Ethica da EDUFSC.

Desde a criação da Bioética, então, o debate sobre as suas principais questões filosóficas por ela fomentadas cresceu muito. Somente para citar a participação ativa de alguns outros filósofos: 
$|100|$

Filosofia e bioética no debate público brasileiro

o australiano Peter Singer publica Animal Liberation, em 1975, condenando o especismo e revolucionando o cuidado humano para com os animais; em 1983, Tom Regan também publica trabalhos defendendo os direitos dos animais argumentando pelo abolicionismo e o vegetarianismo; em 1993, Ronald Dworkin, a partir da decisão da Suprema Corte norte-americana de tornar inconstitucional a proibição do aborto nos EUA a partir do caso Roe v. Wade (1973) discute, em Life's Dominion, questões relacionadas com a interrupção de gestações e a eutanásia defendendo a descriminalização do aborto no primeiro trimestre de gravidez. $\mathrm{Na}$ Inglaterra, Mary Warnock participa da discussão sobre o status do embrião e publica-se o relatório que leva o seu nome, "Warnock Report", defendendo pesquisa com embriões até o $14^{\circ}$ dia. Richard Hare é outro importante filósofo inglês que se manifesta publicamente sobre questões bioéticas. Mais recentemente, Habermas publica o livro O Futuro da Natureza Humana expressando a sua visão sobre questões relacionadas com a clonagem e a eugenia. Esses são exemplos do efetivo envolvimento de filósofos em discussões públicas sobre questões bioéticas.

Para finalizar a apresentação da participação de filósofos em debates bioéticos, gostaria de mencionar o The Philosopher's Brief, escrito por seis eminentes filósofos: Ronald Dworkin, Thomas Nagel, Robert Nozick, John Rawls, Thomas Scanlon and Judith Jarvis Thomson, sobre a questão de se pacientes possuem o direito ao suicídio assistido ou não. Em 1997, a Suprema Corte norteamericana teve que julgar o pedido de proibição da possibilidade de médicos prescreverem injeção letal ou praticarem atos à la Kevorkian, o conhecido "doutor morte". Os filósofos acima relacionados prepararam um amicus curiae argumentando que os indivíduos têm um direito constitucional (nos EUA) de escolher e tomar decisões pessoais sobre o modo como eles querem morrer. Eles reconhecem que o Estado tem interesses importantes para regular o suicídio assistido, mas esses interesses não justificam uma proibição absoluta. Note-se, então, o envolvimento de vários filósofos no debate público sobre questões bioéticas. Algo similar aconteceu no Brasil: vários filósofos foram citados no amicus 
curiae formulado pela MOVITAE no questionamento da inconstitucionalidade da Lei de Biossegurança. Essa lei será discutida na última parte deste artigo.

No Brasil, a Bioética ficou, no início, restrita à atuação de profissionais da saúde e religiosos e chegou mais de vinte anos depois de seu surgimento. É comum caracterizar a Bioética no Brasil como "jovem e tardia" (Dos Anjos e Siqueira, 2007). Em meados da década de 1990, destaca-se o trabalho do médico William Saad Hossne que preside a Comissão Nacional de Ética na Pesquisa elaborando a já mencionada Resolução 196/96. O primeiro livro de Bioética publicado no nosso país por pensadores brasileiros é desse período, a saber, Problemas Atuais de Bioética, do padre Léo Pessini e do enfermeiro Christian de Paul de Barchifontaine, publicado originalmente em 1991. Em 1995, oficializou-se a Sociedade Brasileira de Bioética (http://www.sbbioetica.org.br/), presidida por William Saad Hossne, um marco certamente muito importante para a consolidação da Bioética no Brasil. Nesse mesmo período, mais precisamente em 1993, o Conselho Federal de Medicina (http:/ /portal.cfm.org.br/) começa a publicar a Revista Bioética e, em 1998, o livro Iniciação à Bioética, uma das melhores introduções que temos na área, com a participação de vários profissionais incluindo trabalhos de filósofos, por exemplo, de Franklin Leopoldo e Silva e Joaquim Clotet. Nesse período, merece destaque também a criação do Portal de Bioética da UFRGS (http://www.bioetica.ufrgs.br/), em 1997, um excelente instrumento dedicado ao ensino e à pesquisa da Bioética coordenado pelo médico e professor José Roberto Goldim. Em 1999, dois fatos marcam a introdução oficial, no contexto filosófico, da Bioética na Universidade Federal de Santa Catariana: i) a criação do Núcleo de Estudos e Pesquisas em Bioética, coordenado pelo Prof. Bonifácio Bertoldi com a participação da Profa. Sônia T. Felipe e mais tarde dos professores Darlei Dall'Agnol e Delamar Volpato Dutra; ii) a criação da disciplina "Fundamentos Filosóficos em Bioética", talvez uma das primeiras nos cursos de filosofia no Brasil. Um fato marcante no desenvolvimento da Bioética no Brasil foi a realização, em 2002, na cidade de Brasília, do VI Congresso Mundial de Bioética da 
$|102|$

Filosofia e bioética no debate público brasileiro

International Association of Bioethics, cuja publicação do livro Bioética, Poder e Injustiça, organizado por Volnei Garrafa e Léo Pessini, conta com vários trabalhos de filósofos (americanos, canadenses, chilenos, ingleses, portugueses, filipinos, alemães, argentinos, colombianos, etc.), com destaque para um brasileiro: Olinto Antonio Pegoraro. Em 2005, a Sociedade Brasileira de Bioética lançou a Revista Brasileira de Bioética. Em 2007, editou-se o livro Bioética no Brasil, organizado pelo teólogo Márcio Fabri dos Anjos e pelo médico José Eduardo de Siqueira apresentando as principais tendências e perspectivas da "contribuição brasileira para a Bioética mundial". Nele encontram-se reflexões filosóficas tanto sobre as bases epistemológicas quanto sobre os problemas éticos da "Bioética brasileira" além de um levantamento sobre as principais produções bibliográficas e dos principais centros de pesquisa em Bioética do país. De acordo com um dos trabalhos, existem seis escolas do pensamento bioético brasileiro: 1) a Bioética de Reflexão Autônoma (desenvolvida pelo médico Marco Segre e outros); ii) a Bioética da Proteção (criada pelo "filósofo Fermin Roland Schramm"); iii) a Bioética de Intervenção (capitaneada pelo odontólogo Volnei Garrafa); iv) a Bioética e Teologia da Libertação (pregada pelo teólogo Márcio Fabri dos Anjos); v) a Bioética Feminista (defendida pela antropóloga Débora Diniz) e, finalmente, vi) a Bioética Ambiental (propagada pelo teólogo José Roque Jungues) (cf. Siqueira et alii, 2007, p. 163 ss.) Algumas delas serão brevemente comentadas a seguir. Nesse mesmo livro, num levantamento da produção científica na área da Bioética afirma-se que "muitos filósofos têm produzido obras importantes na área" (p. 218) e menciona-se, em especial, os nomes de Newton Aquiles Von Zuben, da Unicamp, e Franklin Leopoldo e Silva da Silva, da USP. Também em 2007, o Centro Universitário São Camilo passa a publicar a revista Bioethikos. Essa instituição foi a responsável por implantar o primeiro Curso de Mestrado em bioética em 2004 e o Doutorado em 2010. Além dela, há um doutorado interinstitucional (numa associação entre a FIOCRUZ, a UFRJ, a UFF e a UERJ), com a participação de profissionais da filosofia, por exemplo, da Profa. Maria Clara Dias. Outro doutorado 
em Bioética existe na Universidade de Brasília, coordenado por Volnei Garrafa, com apoio da UNESCO. Também é importante salientar que alguns programas de pós-graduação, seja na área das ciências da saúde seja nas ciências sociais e humanas, incluindo a filosofia, também possibilitaram a apresentação de dissertações e teses sobre temas bioéticos. Por exemplo, entre 2002 e 2004 orientei a primeira dissertação no PPGF da UFSC sobre um tema bioético "O valor intrínseco da vida e a autonomia: reflexões sobre a eutanásia", defendida por Sandra Campi. Acredito que muitos outros trabalhos sobre temas bioéticos tenham sido defendidos nos programas de pós-graduação em filosofia recentemente. Essa também é uma forma importante de participação de filósofos em debates sobre temas bioéticos.

É importante ressaltar que a Bioética, no nosso país, tentou encontrar um caminho teórico (e prático) próprio, mas até agora as tentativas não estão completamente consolidadas. Não é muito claro em que sentido o pensamento latino-americano, ou particularmente o brasileiro, pode contribuir para a discussão bioética. Claro que a nossa realidade social e econômica não é a dos países desenvolvidos e que questões de justiça são proeminentes, mas não elaboramos ainda um pensamento bioético próprio. Por exemplo, defender que o sistema sanitário privilegie quando necessário os menos favorecidos com a finalidade de reduzir as injustiças naturalmente existentes na nossa sociedade encontra sua fundamentação na teoria da justiça como equidade de Rawls aplicada à Bioética por Daniels, Beauchamp e Childress, entre outros. Talvez haja alguma verdade na afirmação de que o principialismo seja mais adequado à realidade norte-americana que valoriza a autonomia individual, mas isso não invalida a teoria que funciona com normas prima facie e que é bastante flexível permitindo a adaptação às nossas circunstâncias e contextos. Por conseguinte, a crítica é em certo sentido descabida, pois, ao contrário, na versão de Beauchamp e Childress do principialismo, nega-se expressamente a priorização da autonomia. É somente Tristian Engelhardt quem dá prioridade à autonomia em relação à beneficência. Há tentativas também de pensar questões mais proeminentes para países considerados periféricos em relação 
|104|

Filosofia e bioética no debate público brasileiro

à Europa, EUA e outros países desenvolvidos. Nesse sentido, Volnei Garrafa (2003) defendeu uma "bioética dura", uma "bioética de intervenção", com ênfase especial para as questões de justiça num mundo globalizado precisando de uma ética da "responsabilidade solidária". Outro exemplo: quando questionei William Saad Hossne, num congresso em Florianópolis em que refletia criticamente sobre a insuficiência dos quatro princípios mencionados acima (ou do principialismo), sobre qual princípio ele acrescentaria à Resolução 196, ele afirmou que seria a solidariedade. O problema consiste, todavia, em distinguir e, então, equacionar satisfatoriamente a obrigação de beneficência com a solidariedade. De fato, talvez os povos latinos sejam mais solidários que os anglo-americanos, mas a relação entre questões de autonomia e de justiça precisam caminhar lado a lado com questões de solidariedade e beneficência.

Há, certamente, vários profissionais de distintas áreas que trabalham questões bioéticas no nosso país. Por exemplo, a perspectiva feminista é bastante desenvolvida pela antropóloga Débora Diniz, que também participou do livro Iniciação à Bioética e tem se destacado como militante fazendo uma série de vídeos importantes sobre temas bioéticos. Além disso, inúmeras áreas da saúde, não apenas a medicina ou a própria enfermagem, enfrentam problemas bioéticos, tais como a odontologia, a psicologia, etc. É importante ressaltar, então, que há pessoas com formação filosófica atuando nessas áreas, principalmente, em programas de pós-graduação. Por exemplo, na Universidade Federal de Uberlândia, Alcino Bonella trabalha na linha "Bioética e Qualidade de Vida" do Doutorado em Ciências da Saúde.

E a filosofia, então, o que tem feito pela Bioética no nosso país? No entendimento de Volpato Dutra, "no Brasil, a filosofia só se aproximou da bioética no início do século XXI e fê-lo de forma tímida. Exemplos dessa aproximação são os trabalhos de Joaquim Clotet, Sonia Felipe, Darlei Dall'Agnol, Alcino Bonella, dentre outros" (2011, p. 7). É claro que uma lista completa é difícil de fazer e corre o risco de deixar de fora outros nomes importantes, mas pode-se acrescentar os trabalhos de Marco Antonio de Azevedo 
(RS), Álvaro Montenegro Valls (RS), Franklin Leopoldo e Silva (SP), Maria Clara Dias (RJ), Olinto A. Pegoraro (RJ), José N. Heck (GO), Cinara Nahra (RN), Lincoln Frias (MG), etc., novamente, "entre outros", pois conheço melhor a realidade catarinense (cf. também Shlempter, 2012). O objetivo, entretanto, não é fazer uma enumeração exaustiva, mas mostrar como vários filósofos brasileiros estão se envolvendo cada vez mais no debate público sobre problemas bioéticos. Outro exemplo é a publicação do livro, organizado por Ricardo Timm de Souza e Nythamar Fernandes de Oliveira: Fenomenologia Hoje III: Bioética, Biotecnologia, Biopolítica. Há, certamente, muitos outros.

\section{2 - O que pode a filosofia fazer pela Bioética?}

Na seção anterior, foi apresentada uma breve história do surgimento e desenvolvimento da Bioética com alguns destaques para a participação de filósofos nesse processo. Nesta seção, vou apresentar algumas contribuições que a filosofia pode, segundo meu entendimento, fazer na discussão pública sobre temas bioéticos. Para alguns pensadores, a filosofia nada pode fazer pela Bioética, mas discordo dessa posição e argumentarei contra essa visão cética e pessimista.

Para começar, gostaria de ressaltar que considero a Bioética parte da ética aplicada que, juntamente com a metaética e a ética normativa, formam os principais domínios da própria ética (cf. Dall'Agnol, 2005, para mais detalhes sobre essa divisão tríplice). Nesse sentido, discordo de meu amigo, o médico e filósofo Marco Antonio de Azevedo. Ele questiona se faz sentido considerar a Bioética parte da filosofia e responde categoricamente: "Certamente, não." A principal razão apresentada por Azevedo é que a Bioética nasceu "fora do meio acadêmico filosófico" (Azevedo, acesso em 2012, cf. bibliografia). Embora isso possa ser parcialmente verdadeiro, não se segue que as reflexões que levaram ao nascimento da Bioética não tenham sido filosóficas ou claramente influenciadas por filósofos. Esse certamente foi o caso, como a primeira seção deste artigo deve ter mostrado, nos 
$|106|$

Filosofia e bioética no debate público brasileiro

trabalhos tanto dos criadores da Bioética Geral, Jahr, Potter, etc. quanto da Bioética Clínica ou de suas aplicações na pesquisa biomédica feitas por Callahan, Jonsen, Beauchamp, Pellegrino, etc. É sempre bom lembrar que Potter concebeu a Bioética como um tipo novo de sabedoria. Nada mais filosófico, portanto.

A questão importante, então, é esta: o que a filosofia pode fazer pela Bioética? Claro que, sendo a Bioética parte da ética que por sua vez é parte da filosofia, uma resposta a essa questão depende muito de uma compreensão sobre a própria natureza da atividade filosófica e do que "a filosofia pode fazer por si mesma". Para não entrar numa regressão indefinida nesse debate, vou adotar a caracterização das possíveis contribuições da filosofia no âmbito da Bioética a partir do já mencionado filósofo Daniel Callahan. No artigo "Bioethics as a Discipline", de 1974, portanto antes do surgimento da Bioética enquanto disciplina ou campo de estudos, Callahan sustenta que, "se uma disciplina como a Bioética deve ser criada", ela trará para o bioeticista três tarefas a serem executadas: "definições de conceitos, estratégicas metodológicas e procedimentos para a tomada de decisões" (1997, p. 19). De fato, essas são tarefas importantíssimas e, de acordo com Callahan, filósofos e teólogos recebem treinamento para desempenhá-las bem. Eu gostaria de acrescentar que a análise de conceitos leva a boas definições, que a clarificação de princípios, a análise de argumentos vendo as conexões lógicas entre premissas e a conclusão e a formação de sistemas normativos também são possíveis contribuições filosóficas para a resolução de problemas bioéticos. Outro pensador, o único filósofo integrante efetivo da mencionada "National Commission" norte-americana, Albert Jonsen, também sustenta que uma das contribuições mais importantes que a filosofia pode proporcionar é exatamente a de "clarificar conceitos" (Jonsen, 2003, p. 65). Certamente, muito do que os filósofos participantes daquela comissão fizeram foi clarificar conceitos e propor princípios bioéticos. Por conseguinte, pensar problemas bioéticos é uma atividade eminentemente filosófica.

Para ilustrar em que medida a filosofia pode contribuir com as discussões bioéticas, vou apresentar uma efetiva contribuição 
em termos de clarificação conceitual feita por Beauchamp e Childress (2009, p. 101), a saber, do conceito de autonomia. Reconhecidamente, a introdução da autonomia na base da Bioética representou a revolução mais significativa da ética (bio)médica desde a adoção da tradição hipocrática há XXV séculos. É claro que a autonomia como princípio moral surgiu já na modernidade com os filósofos Immanuel Kant e John Stuart Mill, mas ela foi, como vimos na primeira seção, incorporada somente na década de 1970 na medicina e não sem a luta pelos direitos humanos e as reivindicações de movimentos sociais. No Brasil, ela somente foi incorporada oficialmente na Ética Médica em 2010, por exemplo, no Art. 41 que será comentado na próxima seção. Mas a questão filosófica é: o que significa autonomia ou ação autônoma? Para Beauchamp e Childress, as condições necessárias e suficientes para considerar um agente autônomo são: (i) capacidade de agir intencionalmente, (ii) entendimento das circunstâncias da ação e (iii) liberdade em relação a influências externas. Essa é uma forma clara de analisar um conceito permitindo uma definição precisa de autonomia. Por conseguinte, prevaleceu uma concepção milliana e não kantiana de autonomia na Bioética. Feitas a análise conceitual e a definição, é possível formular claramente um princípio normativo. Feita a análise conceitual e estabelecido o princípio é também possível, como fazem os bioeticistas brasileiros, perguntar-se sobre como entender a autonomia em um país marcado pela marginalização e discriminação, por diferentes formas de pobreza e pelo desamparo social. Além disso, também é possível questionar, desde o ponto de vista feminista, se a autonomia pode ser entendida de forma não relacional. Essas discussões críticas são tarefas eminentemente filosóficas.

Outra contribuição em termos de clarificação conceitual feita por Beauchamp e Childress (2009, pp. 120-121) consistiu no esclarecimento das condições do consentimento informado, o documento que materializa as exigências da autonomia. São elas: (i) competência para entender e decidir; (ii) a voluntariedade na tomada de decisão (iii) efetiva revelação ao paciente ou sujeito de uma pesquisa das informações relevantes de sua condição ou 
$|108|$

Filosofia e bioética no debate público brasileiro

participação na pesquisa; (iv) a recomendação de um plano de ação; (v) a compreensão, por exemplo, do diagnóstico e dos prognósticos ou riscos envolvidos na pesquisa; (vi) decisão por um plano de ação e (vii) a explícita autorização. Esse é um exemplo de uma efetiva contribuição filosófica para a Bioética. Há inúmeros outros conceitos aguardando clarificação e também outros documentos que aplicam a autonomia aos processos de final de vida e alguns deles serão mencionados na última parte do presente trabalho.

Para não ficar somente nas contribuições dos filósofos fundadores da Bioética, vou ilustrar aqui outra tarefa filosófica importante no que diz respeito aos debates públicos sobre temas bioéticos, a saber, a análise de argumentos, ou seja, no exame crítico das conexões lógicas (ou a falta delas) entre premissas, na avaliação das pressuposições implícitas das premissas para aceitá-las ou rejeitá-las, na discussão sobre se a conclusão se segue ou não das premissas, etc. Para exemplificar, vou citar a reconstrução feita por Lincoln Frias do "Argumento da Desigualdade" usado por antiselecionistas, isto é, por pessoas que são contra a seleção de embriões feita em procedimentos de fecundação humana in vitro porque isso aumentaria a desigualdade e, portanto, geraria uma sociedade ainda mais injusta. $\mathrm{O}$ argumento seria o seguinte:

P1 - A seleção de embriões é muito cara (e provavelmente não deixará de ser).

P2 - Se for disseminada, ela será usada predominantemente por ricos.

C1 - A seleção de embriões aumentará a desigualdade social.

P3 - Os ricos já têm muitas vantagens sobre os pobres.

P4 - É injusto que exista desigualdade social muito grande.

C2 - A seleção de embriões é injusta.

C3 - A seleção de embriões não deve ser permitida. (Frias, 2012, p. 150)

Uma tarefa filosófica importante é analisar criticamente esse argumento. O próprio Frias sustenta que há vários motivos para rejeitar algumas premissas. Ele procura mostrar que "a primeira parte da P2 não é plausível”; que "não está claro quais características 
que poderiam ser selecionadas dariam vantagens imorais aos ricos"; que "nem toda desigualdade é injusta" e assim por diante (cf. Frias, 2012, p. 151 ss.). O que vemos, aqui, é um exame crítico das premissas do argumento com a consequente rejeição das conclusões. Essa é uma tarefa tipicamente filosófica valiosíssima com implicações importantes para as questões bioéticas ou de biodireito, etc. Alguém poderia discordar da posição de Frias e defender ou reformular o argumento acima. Afinal, o incremento da beleza, da força física, das aptidões intelectuais, etc. parece de fato contribuir para o aumento da desigualdade. Desse modo, o debate público sobre a seleção de embriões continuaria. Esta é uma forma fundamental de participação da filosofia no debate público.

Sobre a sugestão de que filósofos podem auxiliar construindo sistemas normativos para a Bioética, basta lembrar que a teoria predominante foi precisamente proposta por filósofos. Nesse sentido, a combinação de princípios éticos deontológicos tais como o respeito pela autonomia e o princípio da justiça com princípios teleológicos ou consequencialistas como o da beneficência e o da não maleficência, todos valendo prima facie e deixando a decisão sobre a aplicação para um exame detalhado de casos, é originalíssimo, superando as teorias éticas tradicionais como as de Kant ou Mill. Claro que esse enfoque normativo na Bioética tem os seus problemas, por exemplo, pode gerar dilemas morais. Além disso, ele foi acusado de ser muito geral, abstrato, etc., lembrando as críticas hegelianas à ética de Kant. Todavia, o método da especificação (detalhamento de regras que se seguem dos princípios) ajuda a minimizar esse problema. Claro que há ainda os insatisfeitos com a especificação e discordam do método de partir de princípios defendendo uma análise casuística. Os filósofos já mencionados Albert Jonsen e Stephen Toulmin são exemplos de casuístas, ou seja, que valorizam a análise detalhada dos casos e negam a existência de princípios (bio)éticos universais. Preferem, antes, apostar na velha e boa prudência ou sabedoria prática aristotélica para decidir, a partir da percepção dos detalhes do caso analisado, o que tem que ser feito. 
$|110|$

Filosofia e bioética no debate público brasileiro

Como pode ser visto, filósofos também podem contribuir com a discussão de problemas metodológicos da Bioética: devemos partir de princípios ou da análise de casos (casuística)? Existe uma terceira via? O método do Equilíbrio Reflexivo, proposto por um dos maiores filósofos morais e políticos do final do século XX, John Rawls, é um procedimento que, grosso modo, exige a aplicação de princípios a casos e a análise de casos a partir de princípios. Vários bioeticistas utilizam esse método em seus trabalhos como, por exemplo, Norman Daniels. Esse procedimento foi incorporado a partir de alguma edição do Principles of Biomedical Ethics por Beauchamp e Childress, que inicialmente usava um método puramente dedutivo, de "cima para baixo", ou seja, de aplicação de princípios a casos. Enfim, problemas metodológicos da Bioética também podem ser discutidos por filósofos de quem se espera uma efetiva contribuição.

Se alguém, agora, perguntar se filósofos devem se manifestar sobre problemas bioéticos substanciais, por exemplo, sobre questões relacionadas com o início da vida (selecionar ou não embriões, interromper ou não gestações, etc.), o meio da vida (qualidade de vida, xenotransplantes, etc.) e final de vida (ser a favor ou contra suicídio assistido, eutanásia ativa não voluntária, etc.), minha resposta é "Certamente, sim". Tradicionalmente, como foi dito acima, os grandes filósofos manifestaram-se sobre esse tipo de questão. Todavia, a perspectiva deve ser eminentemente filosófica, com uma sólida base metaética e com um enfoque normativo claramente fundamentado. Os problemas metaéticos têm prioridade para um filósofo enquanto ele exerce a sua atividade profissional, mas os problemas de aplicação possuem prioridade para essa mesma pessoa enquanto cidadã vivendo a sua vida cotidiamente numa comunidade particular. Portanto, priorizar a metaética não implica em descartar os problemas bioéticos. A própria Bioética nasceu a partir da tentativa de Potter de resolver um problema metabioético, a saber, de superar a dicotomia entre fatos biológicos e valores, o chamado "is-ought gap" e, desse modo, unificar ciências naturais e humanas. 
Outra tarefa filosófica importante é contribuir no processo de tomada de decisões que envolvem escolhas bioéticas difíceis. Não se trata de ajudar, por exemplo, um profissional da saúde a decidir rapidamente num momento específico de sua atividade profissional, mas criar mecanismos para que a deliberação e as escolhas sejam as melhores possíveis. Para ilustrar: se um profissional da saúde precisa decidir se pratica ou não a reanimação de um paciente, não é o filósofo que vai dizê-lo num caso particular, mas a decisão pode se basear em procedimentos que são elaborados em "calmos momentos de reflexão", amplamente discutidos e adotados enfim em determinadas situações. Por exemplo, a necessidade de respeitar a vontade do paciente, que deve estar claramente expressa numa espécie de "Testamento Vital", orienta a tomada de uma decisão particular embasada num processo institucionalizado. Nesse sentido, a participação de filósofos em Comitês de Bioética é uma contribuição possível e de fundamental importância.

Filósofos podem participar ativamente de uma série de instituições, não apenas Comitês de Bioética que claramente possuem relação com problemas bioéticos. Por exemplo, nos EUA, Edmund Pellegrino comandou a "Presidential Comission for the Study of Bioethical Issues", um órgão responsável pelo assessoramento ao presidente daquele país sobre temas bioéticos. Um órgão similar deveria ser criado no nosso país, dada a importância atual dos temas bioéticos. Vários filósofos participaram e ainda participam de uma série de comissões que lidam com problemas bioéticos: CEUAs (Comitês de Ética no Uso de Animais), CEPs (Comissões de Ética na Pesquisa), Comitês de Bioética em Hospitais ou Clínicas, etc. Minha própria experiência nesse sentido é que a tarefa não é fácil, mas absolutamente necessária. Por exemplo, quando substituí Sônia T. Felipe no CEUA da UFSC, o comentário era de que não se deveria dar espaço para filósofos, principalmente, abolicionistas. Eu sempre defendi o enfoque baseado nos 3Rs (substitua (replace), reduza e refine) em pesquisas envolvendo animais não humanos e, mesmo assim, foi difícil discutir a eticidade ou não de certos projetos de pesquisa que não traziam contribuição científica e apenas maltratavam 
$\mid 112$ |

Filosofia e bioética no debate público brasileiro

seres vivos sencientes. Hoje, defendo a priorização da substituição o que pode levar um dia à abolição completa do uso de animais em experiências científicas, embora pense que muitas delas ainda se justifiquem no presente desenvolvimento científico e tecnológico. Mas na UFSC de hoje não há mais filósofos atuando no CEUA e isso representa, no meu entendimento, uma perda muito grande. Os comitês de ética não podem se transformar numa defesa corporativista dos interesses de alguns profissionais. Eles tornam-se, então, comitês "antiéticos" de ética.

A efetiva participação de filósofos em debates públicos pode, por conseguinte, se dar de efetivas maneiras. Os exemplos acima já deixam isso bastante claro. Todavia, há outras formas. Não apenas em programas televisivos ou em entrevistas para rádios ou jornais de circulação diária (eu próprio já fiz tudo isso e, certamente, muitos outros filósofos também participaram), mas principalmente através das já mencionadas orientações de dissertações e teses e de publicações de caráter acadêmico tais como revistas especializadas, participação de congressos, elaboração e publicação de livros, etc. Gostaria de mencionar aqui, a título de exemplificação, a edição de um número especial da revista ethic@ sobre clonagem e eugenia que teve grande repercussão pública (http://www.periodicos.ufsc.br/index.php/ethic). Ela estimulou, por exemplo, a realização de estudos mais aprofundados sobre o tema da eugenia e o resultado é a tese agora transformada em livro de Feldhaus (cf. bibliografia). Esses e outros temas bioéticos precisam continuar a ser debatidos publicamente por filósofos.

Para finalizar essa seção, gostaria de mencionar o caráter eminentemente interdisciplinar da Bioética, aspecto já sublinhado por Potter, como foi visto acima. Nesse sentido, é necessário alertar para a "tragédia" que representa ver outros profissionais assumir o trabalho de dar conta da dimensão filosófica de suas áreas assim como é desastroso ver filósofos posando de cientistas ou fazendo ciência para seu próprio consumo sem pesquisa empírica séria. Embora eu defenda que a ética tenha validade universal, o tratamento "inter", "multi" e "trans" disciplinar dos problemas bioéticos ajuda a compreender as suas múltiplas facetas e, 
ultimamente, a mostrar em que medida eles fazem parte de todos os domínios da vida humana. Por conseguinte, somente um efetivo diálogo entre profissionais de saúde e outros cientistas com filósofos (daí a necessidade de debate não apenas para o grande público) manterá a Bioética como ponte.

\section{3 - Alguns problemas bioéticos atuais para o debate público brasileiro}

Nesta última seção, vou apresentar alguns temas bioéticos que aguardam uma participação mais ativa dos filósofos no debate público, principalmente, no contexto brasileiro. Entre eles, gostaria de citar: a elaboração do Código Florestal e outras questões de Ética Ambiental (p. ex., a biopirataria na Amazônia); o uso de animais em experiências científicas e a Lei Arouca; a reforma da Lei de Biossegurança e outros temas de biotecnologia; a questão da reprodução assistida e os problemas de eugenia a ela associada; a retomada da questão do aborto através da discussão do Novo Código Penal; o novo Código de Ética Médica e a necessidade da adoção de um "Testamento Vital" a discussão da questão da eutanásia; a necessidade de aumento na prestação de serviços de cuidado paliativo; a construção de um sistema mais justo de saúde, etc. É claro que não é possível tratar de todos eles aqui e cada um deles mereceria um trabalho próprio, mas a ideia é ilustrar possíveis temas bioéticos para o debate. Cabe alertar, também, que a discussão desses temas encontra resistência por parte dos colegas e, muitas vezes, publicações são "censuradas." É necessário, portanto, coragem intelectual.

Vou iniciar, então, com reflexões sobre alguns desses temas. Como é sabido, a Lei Brasileira de Biossegurança, principalmente no artigo $5^{\circ}$, torna permissível a pesquisa envolvendo células-tronco embrionárias, as totipotentes, mas estabelece duas condições: primeiro, os embriões não devem ser viáveis para reprodução; segundo, eles devem estar congelados há três anos ou mais na data de publicação da norma. A lei proíbe, todavia, no artigo $6^{\circ}$, a produção de embriões para comercialização, a clonagem humana 
$|114|$

Filosofia e bioética no debate público brasileiro

e o uso de engenharia genética em células germinativas, zigotos e embriões humanos. Agora, a referida lei foi questionada em 2005 pelo procurador geral. Ele argumentou que o artigo $5^{\circ}$ seria inconstitucional. A principal razão por ele apresentada foi que a Constituição Brasileira está baseada no princípio da dignidade da pessoa humana (em seu artigo primeiro). Além disso, a Constituição garante o direito à vida (artigo $5^{\circ}$ ) e visto que a vida começa (o procurador aqui argumentou por conta própria) no momento da concepção (quando o espermatozóide fertiliza o óvulo), a lei 11.105/2005 era supostamente inconstitucional. Mas, em maio de 2008, o Supremo Tribunal Federal aceitou a pesquisa com célulastronco embrionárias como sendo legal baseado na tese de que o embrião não é uma pessoa. Mas considere o que podemos chamar de "fertilização tripla": a transferência do núcleo de um embrião não sadio, isto é, com anomalias no DNA mitocondrial para uma base citoplasmática sadia. Sabe-se, hoje, que muitas doenças degenerativas possuem essa causa. É eticamente permissível adotar esse procedimento? A resposta poderia ser negativa se o procedimento implicasse na destruição de embriões, mas considere a fertilização tripla usando outra técnica, a saber, a "spindle transfer". Somente para clarificar: essa técnica envolve a transferência do DNA nuclear de um óvulo (e não de um embrião) para outro óvulo sadio, isto é, sem anomalias genéticas deixando o DNA mitocondrial com problemas para trás. Por que não usar tal técnica permitindo a fertilização tripla para evitar doenças degenerativas graves? Por que, então, não usar engenharia genética em células germinativas humanas? A Lei Brasileira de Biossegurança é muito restritiva e precisa ser reformulada, principalmente, para tornar também permissível, se necessário, pesquisas com células-tronco congeladas depois de 2008. Qual é o sentido de restringir o uso somente de embriões já congelados na data de publicação da Lei de Biossegurança?

Há, todavia, uma série de outras questões bioéticas que poderiam contar com uma participação maior de filósofos no debate público brasileiro. Por exemplo, tramita no Congresso Nacional, há muitos anos, projeto de reforma do Código Penal. Uma das 
mudanças necessárias diz respeito à descriminalização de interrupções de gestação em casos de doenças gravíssimas tais como a anencefalia, entre outras. Atualmente, o Código Penal permite a interrupção apenas para salvar a vida da mãe e em casos de estupro (art. 128). Não há razões morais, numa sociedade secular e pluralista, para obrigar uma gestante a conceber um filho ou uma filha sofrendo anencefalia que certamente não sobreviverá. Há outras doenças detectáveis em diagnósticos pré-natais, tais como Tay-Sachs e similares, que são muito severas e que, em nome do princípio do respeito pela autonomia, deveria ser permitida a interrupção da gestação. Já há jurisprudência suficiente para isso e também sensibilidade social para aceitá-la. $O$ debate que deveria ser aprofundado diz respeito à possibilidade de interrupção, no primeiro trimestre de gravidez, por outros motivos que afetam a futura mãe, como defende o feminismo. Infelizmente, poucos filósofos participam desse debate.

Não são somente questões relacionadas com o início da vida que deveriam, todavia, contar com a contribuição dos filósofos. Por exemplo, apesar da aprovação do novo Código de Ética Médica em 2010, com o avanço proporcionado pelo Art. 41, ainda não foi criado o que se poderia chamar "Testamento Vital" (que, nos EUA, é conhecido como living will desde meados de 1980 e em 1990 foi reconhecido oficialmente pelo Congresso Americano através do The Patient Self-Determination Act) e também as "Diretrizes ou Diretivas Antecipadas" (advance directives) que começam a ser muito discutidas entre os diferentes profissionais da saúde. Antes de analisar esses documentos, convém citar o mencionado artigo:

(É vedado ao médico)

Art. 41. Abreviar a vida do paciente, ainda que a pedido deste ou de seu representante legal.

Parágrafo único. Nos casos de doença incurável e terminal, deve o médico oferecer todos os cuidados paliativos disponíveis sem empreender ações diagnósticas ou terapêuticas inúteis ou obstinadas, levando sempre em consideração a vontade 
$|116|$

Filosofia e bioética no debate público brasileiro

expressa do paciente ou, na sua impossibilidade, a de seu representante legal.

Uma série de questões pode ser feitas aqui. Numa palestra no GT de Ética da ANPOF de 2010, o filósofo Marco Antonio de Azevedo questionou esse artigo a partir da dificuldade de estabelecer o que pode significar "incurável e terminal" no parágrafo acima. Penso que esse é um ponto importante que merece análise conceitual, isto é, filosófica. Outro problema é como estabelecer a linha demarcatória entre ações obstinadas e ações não obstinadas por parte dos profissionais da saúde, ou seja, em que sentido não poderia haver omissão ou até mesmo negligência médica; outra, diz respeito ao que pode ou não ser considerado "fútil" num determinado momento ou não se tudo pode depender de desenvolvimentos no conhecimento científico e da criação de tecnologias cada vez mais revolucionárias de tratamento; outra questão é como melhor oferecer cuidados paliativos, etc. Mas uma das questões bioéticas centrais é se, de fato, o paciente deve ter a palavra final expressa mediante documentos que obrigam o profissional da saúde a respeitá-los.

Para entender melhor esse ponto, vou discutir os mencionados documentos. Num "Testamento Vital", o paciente deixa orientações de como quer ser tratado no final da vida; nas "Diretrizes Antecipadas", além de fazer isso, ele nomeia um representante legal para decidir por ele quando estiver incapacitado de comunicar-se. Ao filósofo caberia discutir as bases éticas desse instrumento, por exemplo, em que medida ele expressa melhor o acima aludido princípio do respeito pela autonomia, uma norma fundamental da Bioética. Claramente, a adoção do Termo de Consentimento Livre e Esclarecido em pesquisas científicas de caráter experimental representou um avanço no sentido de proteger os direitos de um sujeito de pesquisa e também resguardar a eticidade e a responsabilidade do pesquisador. Da mesma maneira, um "Testamento Vital" não apenas resguarda os direitos de um paciente, mas também protege o profissional da saúde de questionamentos judiciais sobre possível omissão ou negligência. Claramente, esses documentos são uma materialização importante do princípio bioético que revolucionou as ciências da saúde no 
final do século XX e enquanto eles não forem aceitos socialmente, adotados e reconhecidos juridicamente, as práticas estão sujeitas a várias arbitrariedades, algumas delas decorrentes das questões acima levantadas.

Outra tarefa filosófica importante relacionada com o final da vida diz respeito a uma clarificação conceitual sofre a diferença, se é que existe, entre deixar morrer e matar. Há muita discussão na bioética brasileira não só sobre a diferença entre tipos de eutanásia (ativa, passiva, voluntária, não voluntária e involuntária), mas também distinções, que não são feitas em outros lugares do mundo, entre eutanásia e "mistanásia", "distanásia", "ortotanásia", "cacotanásia", etc. Seria essa uma contribuição da bioética brasileira? Não é muito claro em que sentido. Por isso, é necessária aqui uma análise filosófica mais aprofundada. Aparentemente, há muita confusão no uso desses termos e é uma tarefa importantíssima para um filósofo fazer uma análise clara, com rigor, desses conceitos. Por exemplo: em que medida a ortotanásia não é sinônimo de eutanásia voluntária passiva? Qual é a diferença real, tanto no sentido conceitual quanto prático, entre elas?

Para encerrar, sem entretanto ter a pretensão de ter esgotado as sugestões de possíveis temas para o debate público brasileiro, gostaria de apontar para a necessidade de uma discussão mais aprofundada sobre o nosso Sistema Único de Saúde. Em muitas coisas, ele serve de modelo internacional (distribuição gratuita de remédios), mas, infelizmente, em outras anda muito mal. Não é necessário aqui elencar os problemas. A questão a ser enfrentada é como garantir, de fato, o direito a um padrão mínimo decente de saúde para todos. Alguns bioeticistas, por exemplo Beauchamp e Childress, defendem um sistema misto como sendo o mais justo. Tal sistema seria composto por duas esferas: a) primeira esfera: cobertura social/ estatal universal para necessidades básicas de saúde, ou seja, acesso igualitário aos recursos fundamentais do sistema de saúde; b) segunda esfera: cobertura privada para as outras necessidades e desejos (por exemplo, luxuosas). Não vou discutir aqui em detalhes em que medida o SUS aproxima-se desse modelo ou não e o que precisaria ser mudado. Todavia, é importante considerar, por exemplo, a crescente judicialização do atendimento, e perguntar 
$|118|$

Filosofia e bioética no debate público brasileiro

em que medida ela não fere o princípio da justiça como equidade. É escandaloso saber que grande parte dos recursos do SUS é consumida por pessoas com capacidade de cobrir seus gastos. Também merece questionamento o fato de que Estados mais ricos da federação recebam mais recursos per capita em relação a Estados mais pobres. Esse também é um tópico de Bioética aguardando contribuições de filósofos brasileiros. Enfim, há inúmeros outros...

\section{Observações finais}

Como foi mostrado na primeira seção deste artigo, a filosofia contribuiu para o nascimento e consolidação da Bioética. Já na segunda seção, mostrou-se que há várias tarefas importantes que podem ser desempenhadas pelo filósofo na discussão pública de problemas bioéticos que precisam ser enfrentados na sua interdisciplinaridade. Finalmente, ilustrou-se, na terceira parte, uma série de questões que precisam de uma participação mais ativa de filósofos no contexto brasileiro, apesar do fato de que ela esteja crescendo.

Para finalizar, gostaria, de salientar que, sendo a Bioética parte da ética e, por conseguinte, da própria filosofia, não há razões para que filósofos não se envolvam nos debates públicos sobre questões bioéticas. Estas são questões que interessam a todos os cidadãos e contam com contribuições de múltiplas outras áreas do conhecimento não apenas das ciências biológicas ou da saúde, mas de muitas ciências humanas e sociais tais como a antropologia, a sociologia, o direito, etc. Não se pode, portanto, confundir Bioética com ética médica. A Bioética trata de questões que são universais e, nesse sentido, interessam a todos os participantes do debate público, incluindo filósofos.

\section{Bibliografia}

AZEVEDO, M. A. Bioética fundamental. Porto Alegre: Tomo Editorial, 2002. 
AZEVEDO, M. O papel da filosofia junto à bioética. http:// pt.scribd.com/doc/6655020/Marco-Azevedo-IPA, acesso em 21/03/2012.

BEAUCHAMP, T. e CHILDRESS, J. Principles of Biomedical Ethics. Sixth Edition. New York: Oxford University Press, 2009.

BONAMIGO, E. L. Manual de Bioética. Teoria e Prática. São Paulo: All Print Editora, 2011.

CALLAHAN, D. "Bioethics as a Discipline". In: JECKER, N. S.; JONSEN, A. R. e PEARLMAN, R. A. Bioethics. An Introduction to the History, Methods, and Practice. Massachusetts: Jones and Bartlett Publishers, pp. 17-22. 2007.

CLOTET, J. Bioética: uma aproximação. Porto Alege: Edipucs, 2003.

COSTA, S. I. F.; GARRAFA, V. e OSELKA, G. (orgs.). Iniciação à Bioética. Brasília: Conselho Federal de Medicina, 1998.

DALL'AGNOL, D. Bioética. Rio de Janeiro: Zahar, 2005.

Bioética: Princípios morais e aplicações. Rio de Janeiro: DP\&A, 2005.

DANIELS, N. Just Health Care. Cambridge: Cambridge University Press, 1985.

DOS ANJOS, M. F. e SIQUEIRA, J. E. Bioética no Brasil: Tendências e Perspectivas. Aparecida/São Paulo: Idéias \& Letras/Sociedade Brasileira de Bioética, 2007.

DWORKIN, R. Life's Dominion. An Argument about Abortion, Euthanasia and Individual Freedom. New York: Vintage Books, 1994.

DWORKIN, R. et al. "The Philosophers' Brief". In: JECKER, N. S.; JONSEN, A. R. e PEARLMAN, R. A. Bioethics. An Introduction to the History, Methods, and Practice. Massachusetts: Jones and Bartlett Publishers, pp. 490-502. 2007.

ENGELHARDT, T. The Foundations of Bioethics. Oxford: University Press, 1996. 
$|120|$

Filosofia e bioética no debate público brasileiro

FELDHAUS, C. Natureza Humana, Liberdade e Justiça. Um estudo a respeito da posição de Habermas acerca da biotécnica. Curitiva: Editora CRV, 2011.

FELIPE, S. Por uma Questão de Princípios: Alcance e Limites da Ética de Peter Singer em Defesa dos Animais. Florianópolis: Boiteux, 2003.

FELIPE, S. Ética e Experimentação Animal. Fundamentos Abolicionistas. Florianópolis: Editora da UFSC, 2007.

FRIAS, L. A Ética do Uso e da Seleção de Embriões. Florianópolis: Edufsc. (Série Ethica), 2012.

GARRAFA, V. e PESSINI, L. Bioética: Poder e Injustiça. São Paulo: Edições Loyola/Centro Universitário São Camilo/Sociedade Brasileira de Bioética, 2003.

JAHR, F. "Bioética". Bioethikos, v. 5, n. 3, jul/set., pp. 243-245. 2011.

JONSEN, A. R. The Birth of Bioethics. New York: Oxford University Press, 2003.

JUNGES, J. R. Bioética. Perspectiva e Desafios. São Leopoldo: Edunisinos, 1999.

HABERMAS, J. Die Zufunft der menschlichen Natur. Auf dem Weg zu einer liberalen Eugenik?. Frankfurt: Suhrkamp, 2001.

HARE, R. Essays on Bioethics. Oxford: Clarendon Press, 1993.

HECK, J. Bioética: Autopreservação, enigmas e responsabilidade. Florianópolis: Edufsc. (Série Ethica), 2011.

NEDEL, J. Ética Aplicada. Pontos e Contrapontos. Unisinos: Editora da Unisinos, 2004.

PEGORARO, O. Ética e Bioética. Petrópolis: Vozes, 2002.

PESSINI, L. e BARCHIFOINTAINE, C. P. Problemas atuais de Bioética, $9^{a}$ ed. São Paulo: Loyola, Centro Universitário São Camilo, 2010. 
PELLEGRINO, E. e THOMASMA, D. For the Patient's Good. The Restoration of Beneficence in Health Care. New York: Oxford University Press, 1988.

POTTER, V. R. Bioethics. Bridge to the Future. New Jersey PrenticeHall, 1971.

OLIVEIRA, N. F. e SOUZA, R. T. (orgs.). Fenomenologia Hoje III: Biética, Biotecnologia, Biopolítica. Porto Alegre: Edipucrs, 2008.

REGAN, T. The Case for Animal Rights. Berkeley: University of California Press, 1985.

SHLEMPTER, B. D. "Breve História da Bioética em Santa Catarina". Revista Arquivos Catarinenses de Medicina, março/ abril (no prelo), 2012.

SINGER, P. Animal Liberation. New York: Avon Books, 1991.

Ética Prática. São Paulo: Martins Fontes, 1994.

SIQUEIRA, J. E. et alii. "Linhas temáticas da Bioética no Brasil". In: DOS ANJOS, M. F. e SIQUEIRA, J. E. Bioética no Brasil: Tendências e Perspectivas. Aparecida/São Paulo: Idéias \& Letras/ Sociedade Brasileira de Bioética, pp. 161-184, 2007.

TOULMIN, S. "How Medicine Saved the Life of Ethics". In: JECKER, N. S.; JONSEN, A. R. e PEARLMAN, R. A. Bioethics. An introduction to the History, Methods, and Practice. Massachusetts: Jones and Bartlett Publishers, pp. 26-34. 2007.

VALLS, A. M. Da Ética à Bioética. Petrópolis: Vozes, 2004.

VOLPATO DUTRA, D. J. Razão e Consenso em Habermas. A Teoria Discursiva da Verdade, da Moral, do Direito e da Biotecnologia. Florianópolis, EDUFSC. (Série Ethica), 2005.

"Prefácio: Entre medo e liberdade: contornos da Bioética segundo Heck". In: HECK, J. Bioética: Autopreservação, enigmas e responsabilidade. Florianópolis: Edufsc, pp. 7-10. (Série Ethica), 2011. 